\title{
Evolução recente e novos rumos da literatura sobre integração financeira
}

Milton André Stella ${ }^{1}$

Ronald Otto Hillbrecht ${ }^{2}$

Alexandre Alves Porsse ${ }^{3}$

Resumo: Este artigo faz uma revisão da literatura identificando as principais mudanças ocorridas no foco das discussões relacionadas aos impactos econômicos da integração financeira dos países. As análises deixam de centrar nos impactos diretos e passam a enfatizar também os impactos colaterais deste processo. Além disso, reconhecem o papel das particularidades de cada país no resultado econômico alcançado. Características como o grau de desenvolvimento do setor financeiro doméstico e a qualidade das instituições parecem influenciar nos resultados da integração financeira. Adicionalmente, o estudo indica um conjunto de variáveis institucionais e ações regulatórias que podem auxiliar na alocação mais eficiente dos recursos financeiros e reduzir os riscos dos impactos negativos deste processo.

Palavras-chave: Integração Financeira; Impactos Colaterais; Instituições, Regulamentação.

JEL: F33, F43, F44.

\footnotetext{
1 Doutor em Economia pela Universidade Federal do Rio Grande do Sul - UFGRS e Professor do Departamento de Economia da PUCRS. E-mail: milton.stella@pucrs.br 2 Ph.D., University of Illinois PPGE-UFRGS. E-mail: ottohill@ufrgs.br 3 Doutor em Economia pela UFGRS e Professor do PPGDE/UFPR. E-mail: porsse@ufpr.br
} 


\title{
Recent evolution and new ways for the literature about financial integration
}

\begin{abstract}
This paper does a survey identifying the most important changes in the discussions about the economic impacts of financial integration. The analysis is moving away from the traditional approach centered on the direct impacts of the process and starts to emphasize the collateral impacts of the financial integration process too. The literature also recognizes the role of specific characteristics present in each country to the financial integration outcomes. Characteristics like the local financial sector degree of development and institutional quality seems to have influence in the financial integration results. Additionally, the study indicates a set of institutional variables and regulatory actions that may contribute to make the resources allocation more efficient and reduce the risks of the negative effects of this process to occur.
\end{abstract}

Keywords: Financial integration; Colateral Impacts; Institutions; Regulation.

JEL: F33, F43, F44

\section{Introdução}

A intensificação do processo de integração financeira a partir do final dos anos de 1980, início dos de 1990, desencadeou uma série de estudos a respeito dos seus impactos sobre o desempenho das economias industrializadas e em desenvolvimento. Esse conjunto de estudos, entretanto, não chegou a uma conclusão comum quanto aos seus efeitos, mantendo o questionamento quanto a real capacidade da abertura da conta de capital e financeira ter impactos positivos sobre a atividade econômica.

Segundo Mishkin (2006), o processo de integração econômica entre os países seguiu uma trajetória cíclica ao longo do tempo. A primeira grande era da globalização teria ocorrido no período entre 1870 e 1914, quando a integração comercial teria crescido em torno de $4 \%$ ao ano, passando de $10 \%$ do PIB mundial em 1870 para mais de $20 \%$ em 1914 . Neste mesmo período, o fluxo de capitais cresceu aproximadamente $4,8 \%$ ao ano e saltou de $7 \%$ do PIB mundial para algo próximo de $20 \%$ em 1914. A primeira grande onda de globalização foi acompanhada por uma prosperidade sem precedentes, refletida no aumento da renda per capita que cresceu a uma taxa anual média de $1,3 \%$, enquanto que entre 1820 e 1870 seu desempenho não passou de 0,53\% ao ano. 
Mais importante do que os dados de crescimento do PIB e crescimento da renda per capita ao longo do período, foi a constatação da ocorrência de redução dos diferenciais de renda entre os países desenvolvidos e em desenvolvimento. Países que tinham níveis de renda muito inferiores aos de países ricos e se engajaram no processo de globalização do período em questão, reduziram significativamente estes diferenciais. Estes foram os casos do Japão e da Argentina. O primeiro, após sofrer pressões para abrir a sua economia ao comércio com os EUA, passou a ter crescimento da renda per capita de 1,5\% ao ano em média entre 1870 e 1913, acima da registrada no Reino Unido, de $1 \%$. Assim, a diferença de renda entre os dois países foi reduzida. O caso argentino é ainda mais emblemático, pois o país que registrava renda per capita de aproximadamente $40 \%$ da renda do Reino Unido em 1870 passa para $75 \%$ da renda daquele país em 1913, resultado de uma taxa de crescimento da renda per capita média de $2,5 \%$ ao ano. Por outro lado, países que fizeram o caminho contrário, optando pelo isolamento, como a China, tiveram uma deterioração da renda per capita, caindo de $24 \%$ da renda do Reino Unido para 13\% deste, como apontam Lindert e Willianson (2001).

A primeira onda de globalização foi interrompida pelo início da primeira Guerra Mundial. O conflito provocou reduções drásticas dos fluxos de comércio e de capitais. Entre 1914 e 1939, o comércio internacional caiu de uma média de $22 \%$ do PIB mundial para $16 \%$ e o fluxo de capitais despencou de algo em torno de $20 \%$ para aproximadamente $8 \%$ do PIB mundial.

Além dos problemas causados pela guerra, a economia americana entra em colapso em 1929, gerando efeitos por todo o mundo. Foram 10 anos de estagnação da economia mundial que resultaram no crescimento de correntes fascistas e nazistas na Itália e na Alemanha, culminando com a Segunda Guerra Mundial. O período entre 1939 e 1945 marcou a grande reversão do processo de integração econômica.

A segunda grande onda de globalização começa nos anos de 1960 e se estende até hoje. O processo de retomada inicia em 1944, com o acordo de Bretton Woods, com a criação das instituições financeiras internacionais que teriam a responsabilidade de coordenar esse processo, através do estímulo ao aumento do comércio internacional e da expansão do crédito de longo prazo para a reconstrução dos países europeus destruídos pela guerra e desenvolvimento das economias menos industrializadas.

Nos anos de 1950, o processo de globalização já dava sinais de recuperação e entre 1973 até os dias de hoje o comércio internacional passou de 22\% para $42 \%$ do PIB mundial e os fluxos de capital passaram de $5 \%$ para $21 \%$ do PIB mundial. Entre 1960 até hoje, o crescimento médio da renda per capita ficou em torno de $2 \%$ ao ano, algo nunca antes registrado na história.

Aos críticos, que argumentam que a globalização aumentou a desigualdade de renda entre os países ricos e pobres, Mishkin (2006) responde dizendo que 
há um equivoco na interpretação dos dados econômicos. Se considerarmos os países que realmente buscaram entrar no processo de globalização, como a Coréia do Sul, por exemplo, houve uma brutal redução da desigualdade de renda entre países ricos e os ditos em desenvolvimento. Entretanto, os países que não se inseriram adequadamente no processo de integração, não só perderam renda relativamente aos seus parceiros envolvidos na globalização, como também tiveram queda em termos absolutos nas suas rendas per capita, aumentando a diferença com países desenvolvidos. Desta forma, é claro que quando comparamos os níveis de renda per capita entre os países desenvolvidos com a dos países mais pobres, esta diferença aumenta, pois entre os países de baixo nível de renda predominam aqueles que não entraram no processo de integração comercial e financeiro.

A questão que surge é: se as evidências dos benefícios da globalização são tão contundentes, porque movimentos anti-integração, como os da América Latina, perduram? A questão é que a globalização não gerou resultados homogêneos entre seus participantes. Se, por um lado, existe certo consenso sobre os benefícios da integração comercial, isto é, relativo ao fluxo de bens e serviços entre os países, ainda falta muito para que haja uma opinião mais uniforme quanto aos efeitos da integração financeira. Alguns países como os chamados tigres asiáticos e o Chile, na América Latina, se engajaram no processo e colheram seus frutos, reduzindo significativamente a diferença de renda per capita com os países desenvolvidos. Outros, entretanto, não obtiveram esse resultado e ainda sofreram com crises financeiras intensas, como a Argentina em 2001. Isso indica que talvez algumas pré-condições precisam existir para que os resultados positivos da globalização sejam concretizados.

O objetivo deste estudo é reunir evidências apontadas na literatura econômica acerca dos impactos do processo de integração financeira, seus aspectos positivos, negativos e elementos que podem potencializar os seus benefícios e reduzir a probabilidade de crise. Para tanto, além desta breve introdução, o estudo esta organizado da seguinte forma: na seção dois reunimos evidências apontando os benefícios da integração financeira, tanto por seus canais diretos como por canais indiretos. Na seção três, apontamos a posição dos críticos da globalização. Na quarta seção, reunimos estudos mais recentes que indicam mudanças no foco do debate sobre o tema. Os autores se afastam da discussão de posições mais extremadas sobre os efeitos da abertura financeira, baseadas em relações incondicionais entre fluxos financeiros e crescimento econômico, e analisam diversos fatores que podem afetar o resultado da integração. Na quinta seção, buscamos apontar o que países em desenvolvimento podem fazer para reduzir o lado negativo da integração e potencializar a face positiva deste processo. Por fim, na seção seis, faremos as considerações finais. 


\section{A Integração Financeira pode trazer Benefícios Econômicos?}

Diversos estudos buscaram reunir evidências empíricas quanto a real capacidade de a integração financeira promover benefícios econômicos, principalmente no que se refere à aceleração das taxas de crescimento do produto, conforme apontado em Solow (1956). Neste processo, o primeiro desafio enfrentado pelos autores foi o de definir o que é integração financeira e como medi-la adequadamente, ou seja, qual é a medida correta de integração que deveria ser utilizada nos estudos empíricos. A segunda questão é se diferentes medidas podem alterar as conclusões quanto aos seus impactos econômicos.

\subsection{Principais Medidas de Integração Financeira}

Edison et al. (2004) fazem uma revisão bibliográfica centrada basicamente nos dois pontos mencionados acima. Primeiro testando se diferentes métodos de mensuração do grau de integração financeira podem influenciar os resultados empíricos, e segundo, buscando constatar os impactos dos diferentes grupos de variáveis de controle no resultado da análise.

Os autores identificam onze medidas distintas de integração financeira utilizadas regularmente na literatura sobre o tema. A primeira, e talvez a mais simples, é a utilização das informações contidas no relatório intitulado Annual Report on Exchange Arrangements and Exchange Restrictions (AREAER), publicado pelo Fundo Monetário Internacional (FMI) ${ }^{1}$. Atribui-se, simplesmente, valor zero para países com restrições ao livre fluxo de capitais e valor 1 para países que nunca tiveram esses tipos de restrições. A segunda medida, chamada de share, também deriva do AREAER, mas computa a proporção de anos que o FMI considera que o fluxo de capitais é livre. Mais uma vez, se o país sempre manteve restrições recebe o valor zero e se nunca impôs restrições ao fluxo de capitais recebe o valor 1 . Se, no intervalo de dez anos o país ficou quatro deles sem nenhuma restrição ao fluxo de capitais, então recebe o "grau" 4. A terceira medida foi desenvolvida por Quinn (1997) e está baseada em uma avaliação qualitativa da descrição feita sobre os controles existentes em cada país na base AREAER. Essa descrição enfatiza aspectos que determinam à intensidade das restrições. A leitura é feita por dois pesquisadores de maneira independente e, posteriormente, avaliam as discrepâncias entre as suas notas. A escala vai de zero (mais restritivo) até quatro (menos restritivo). A quarta medida deriva do índice de Quinn. Ela resulta das diferenças no índice para determinados intervalos de tempo.

A quinta medida se aplica somente para países membros da Organização

1 Linha E.2 do referido relatório. 
para a Cooperação e Desenvolvimento Econômico (OCDE) e são publicados no Code of Liberalization of Capital Movements. Cada volume traz informações sobre as restrições impostas ao movimento de capitais em diversas categorias (11) pelos membros da OCDE. Klein e Olivei (1999) construíram uma variável que representa a proporção destes onze itens que são livres de restrição ao longo do tempo. Essa medida pode variar entre zero e 1. Quanto mais próximo de 1 , mais livre o país.

A sexta medida foi desenvolvida por Montiel e Reinhart (1999) e aplica-se para 15 países em desenvolvimento para o período de $1960-96^{2}$. O indicador varia entre zero e 2, e diferentemente dos demais índices apresentados anteriormente, neste caso, quanto maior o valor, mais rígidas são as restrições ao fluxo de capitais. As informações para a construção da medida são retiradas de relatórios anuais dos bancos centrais dos referidos países.

A sétima medida de integração financeira é derivada de informações sobre o grau de liberalização do mercado de ações. Vários estudos dedicaram a sua atenção para o fluxo de ativos financeiros, ao invés de movimentos no mercado de câmbio e de dívida. Levine e Zervos (1998) e Henry (2000a, 200ob), são alguns exemplos de trabalhos que compilaram essas informações a partir dos dados do The Wilson Directory of Emerging Market Funds, do International Finance Corporation (IFC) Investable Indexes, e do The Economist Inteligence Unit, além do AREAER.

Indicadores semelhantes são desenvolvidos por Bekaert (1995) e Beakert e Harvey (1995) que avaliam a abertura financeira a partir de datas em que os países permitem oficialmente mais flexibilidade ao fluxo de capitais. A variável foi construída a partir de relatórios oficiais e por datas estimadas por um modelo de mudança de regime baseado em uma série de dados de fluxos de capitais dos EUA.

Edison e Warnock (2003), por sua vez, criaram outro indicador com o objetivo de capturar o grau de restrição sobre a possibilidade de propriedade estrangeira de ativos nacionais. A medida compreende 29 países emergentes e considerados na fronteira das economias de mercado para os quais o IFC publica dois índices de preços de ativos, o Global (IFCG) e o Investable (IFCI).

Até o momento vimos medidas de integração financeira baseadas principalmente em dados qualitativos, como datas oficiais de mudanças na legislação cambial, abertura de fundos de investimento, entre outros. Alguns autores, por outro lado, questionam a capacidade destas medidas de capturar corretamente o grau de abertura efetivo dos países. A crítica a essa medida é que normalmente elas não conseguem capturar adequadamente o grau de abertura da conta de capital e financeira. Primeiro porque o relatório do FMI, utilizado na maioria dos casos, indica alterações na legislação cambial, que nem sempre impedem ou facilitam o movimento de capitais. Além disso, esta base 2 Os países são: Argentina, Brasil, Chile, Colômbia, Costa Rica, República Tcheca, Egito, Indonésia, Quênia, Malásia, México, Filipinas, Sri Lanka, Tailândia e Uganda. 
não faz o mapeamento de regulamentações que podem interferir nos fluxos financeiros como, por exemplo, a imposição de limites à exposição cambial para bancos comerciais domésticos. A segunda crítica, e talvez a mais séria delas, é que há indícios de que os agentes econômicos conseguem desenvolver mecanismos para burlar a legislação e, portanto, na realidade os movimentos de capital independem, em larga medida, da legislação do país (Carvalho e Garcia, 2006; Magud e Reinhart, 2006; Prasad e Wei, 2007).

Em função das limitações apresentadas acima, uma série de pesquisadores passaram a defender uma forma alternativa de mensuração da abertura financeira. Essas seriam baseadas em medidas de fato, que viriam de alterações ocorridas em determinados preços ou quantidades da economia.

Edison et al. (2004) consideram na sua revisão de literatura as medidas propostas por Kraay (1998) e Lane e Milesi-Ferretti (2001). O primeiro utiliza uma medida anual de entrada e saída de capitais como proporção do PIB do País. Já o segundo adota uma medida um pouco mais restrita de capital, considerando fluxos anuais de portfólios, investimentos diretos e dívida como proporção do PIB. Segundo Eichengreen (2001) são boas medidas de abertura em um determinado ponto no tempo, mas não para períodos muito longos, pois existe uma relação endógena entre fluxo de capital e crescimento econômico e, portanto, esse quociente pode variar demasiadamente ao longo do período analisado.

Recentemente, Rose e Spiegel (2008) utilizam a distância dos países dos grandes centros financeiros internacionais como uma medida de integração financeira. Acreditam que países mais afastados dos grandes centros financeiros internacionais tendem a apresentar maior volatilidade na taxa de crescimento do produto e do consumo agregado (suporta a tese de que países mais próximos dos centros financeiros são financeiramente mais integrados e estes têm menos volatilidade nas taxas de crescimento e consumo). Segundo os autores, esta medida teria uma vantagem de ser completamente exógena em relação a taxa de crescimento do PIB.

\subsection{Integração Financeira, Crescimento Econômico e Impactos Indiretos}

Essa breve descrição das diferentes medidas de integração financeira mostra a complexidade da construção destes indicadores e também permite que os testes empíricos capturem os impactos destas medidas de diferentes formas.

Edison et al. (2004) apresentam os resultados dos testes empíricos de doze estudos, cada um utilizando uma das medidas de integração financeira descritas anteriormente. A conclusão dos autores é a de que os resultados obtidos 
são muito discrepantes e variados, e a explicação para isso pode ter múltiplas fontes. Além das próprias medidas utilizadas como proxy da abertura ao fluxo de capitais terem, potencialmente, impacto no resultado do teste, esse resultado geral pode refletir diversos fatores que distinguem cada um dos testes efetuados, como, por exemplo, diferenças em suas amostras (alguns estudos consideram somente países em desenvolvimento, outros só os países desenvolvidos ou, ainda, uma composição dos dois grupos), horizontes temporais e métodos de estimação.

Dos doze artigos analisados pelos autores, quatro indicam a existência de correlação positiva entre abertura financeira e crescimento econômico. Quinn (1997) foi um dos primeiros a indicar essa relação para uma amostra de 58 países entre 1960 e 1989, utilizando uma regressão cross-section. Klein e Olivei (1999) encontram essa relação positiva para uma amostra de países industrializados, mas não conseguem alcançar a mesma conclusão para os países em desenvolvimento. Apesar de terem encontrado correlação positiva entre abertura financeira e crescimento econômico, para uma amostra de 82 países industrializados e em desenvolvimento, constatou-se que o resultado dependia fortemente dos países da OCDE. Esse mesmo estudo constata que a integração financeira contribui para o desenvolvimento do mercado financeiro, e este é um elemento importante para estimular o crescimento econômico. Ou seja, a abertura da conta de capital poderia contribuir para o crescimento por canais indiretos, como o estímulo a reformas no mercado financeiro.

Nesta mesma linha, Kose et al. (2006) argumentam que uma parcela significativa da influência da abertura financeira sobre o crescimento econômico dos países se deve a efeitos indiretos deste processo, principalmente no que se refere a reformas institucionais e responsabilidade na condução de políticas macroeconômicas. Desta forma, mesmo que num primeiro momento a abertura financeira aumentasse a volatilidade das taxas de crescimento, na medida em que os países fossem ajustando as suas instituições e políticas macroeconômicas passariam a contabilizar os ganhos de crescimento econômico ${ }^{3}$.

Cipriani e Kaminsky (2006) afirmam que a integração financeira fez com que os mercados financeiros se tornassem menos erráticos, reduzindo a volatilidade dos fluxos de capital. Essa redução se deve em parte (25\%) aos fundamentos da economia dos EUA e (10\%) ao nível de volatilidade da taxa de juros norte-americana. Além disso, segundo os autores, os principais choques de fluxos de capitais em países emergentes decorrem de fatores internos.

Outro efeito indireto da integração financeira observado por Henry e Sasson (2008) é o aumento do salário real. O estudo, baseado em uma amostra de 18 países, aponta que nos três primeiros anos após a abertura do mercado financeiro o crescimento médio do salário real no setor de manufaturas aumenta aproximadamente sete vezes. O incremento da produtividade do 3 Ver Kaminsky e Schmukler (2003); Ranciere et al. (2005); Bekaert et al. (2006). Kalemli-Ozcan, Sorensen, Volosovych (2010) encontram aumento na volatilidade do produto associado ao aumento da integração financeira. 
trabalho aumenta ainda mais do que a variação do salário real e tende a ser proporcionalmente maior nos salários dos trabalhadores mais qualificados, gerando possivelmente aumento da desigualdade de renda nos países em desenvolvimento (Henry e Sasson, 2009).

Pires (2006) conclui que a abertura financeira ocorrida no Brasil implicou na imposição de limites a utilização da política fiscal para intervir nos ciclos econômicos. O governo passou a adotar uma política fiscal mais conservadora. Edwards (2001) dá suporte à visão de que a integração financeira promove crescimento econômico. Entretanto, destaca que nem todos os países são beneficiados por esse processo. $\mathrm{O}$ resultado do estudo indica que os países que mais ganham são os de nível de desenvolvimento médio e não os países mais pobres. Esse resultado é corroborado por Klein e Olivei (2005).

Bekaert et al. (2005) utilizam um modelo de dados de painel para comprovar o impacto da integração financeira sobre o crescimento econômico nos países em desenvolvimento. O resultado indica que a liberalização financeira aumenta em 1 ponto percentual por ano a taxa de crescimento do PIB per capita durante um período de cinco anos, ou seja, o impacto ocorreria nos períodos mais próximos da data de abertura financeira.

Ranciere et al. (2006) decompõem os efeitos da liberalização financeira sobre o crescimento dos países. Apesar de reconhecer que este processo aumenta a freqüência de crises financeiras, os ganhos resultados da integração superam largamente os prejuízos causados pelas crises. Na mesma linha, Edwards (2008a, 2008b) indica que apesar de a integração financeira aumentar a probabilidade de crises financeiras, países mais integrados se recuperam mais rapidamente e os mais integrados comercialmente sofrem menos perdas de bem-estar ${ }^{4}$. Kose et al (2008) encontram resultados robustos indicando que a produtividade total dos fatores é positivamente correlacionada com a entrada de investimentos estrangeiros diretos e ativos de portfólio, sendo negativamente correlacionada com a entrada de dívida externa ${ }^{5}$.

Em resumo, esta breve compilação de resultados aponta para três conjuntos de conclusões relacionadas aos efeitos da integração. O primeiro grupo é o que identifica potencial de ganhos sobre a taxa de crescimento diretamente derivados do aumento do fluxo de capitais (ganhos de eficiência alocativa). $\mathrm{O}$ segundo grupo de estudos aponta que os ganhos advindos do processo podem ser de forma indireta, como melhoria na condução da política fiscal, redução da volatilidade do fluxo de capitais, entre outros.

O terceiro resultado indica que a capacidade da integração financeira acelerar a taxa de crescimento econômico dos países não é homogênea entre os países. Esse resultado poderia ser influenciado por diversos fatores, como nível de desenvolvimento institucional, sugerido por Klein (2005), nível de desenvolvimento econômico, apontado em Bekaert et al. (2005), e o número de 4 Prasad (2009) mostra que a abertura gradual implantada na Índia reduziu riscos de crises financeiras. 5 Ver também Bekaert et al (2009). 
grupos de interesse conforme sugere Chandra (2001). Este ponto será objeto de análise na seção quatro.

\section{Abertura da Conta de Capital e Financeira e o Risco de Crise Financeira}

Outros estudos, em contrapartida, além de não encontrarem evidências que suportem os efeitos positivos da integração financeira sobre o crescimento da renda per capita, apontam que a maior liberdade dos fluxos financeiros aumenta a probabilidade de ocorrência de crise financeira, gerando prejuízos econômicos aos países em desenvolvimento. Edison et al. (2004) compilam os resultados de alguns destes. O primeiro deles é o estudo de Grilli e Millesi-Ferretti (1995), que considera taxas médias de crescimento do PIB per capita para cinco sub-períodos de tempo não sobrepostos, cada um com cinco anos, cobrindo o período de 1966 a 1989. A amostra cobre 61 países, apesar de alguns não estarem presentes em todos os sub-períodos. Os resultados são conflitantes e os autores concluem dizendo que o teste não suporta a hipótese de que maior liberdade do fluxo de capitais pode acelerar a taxa de crescimento da renda per capita.

Resultado semelhante é alcançado em Rodrik (1998). Utilizando uma amostra de aproximadamente 100 países, incluindo países em desenvolvimento e desenvolvidos, o autor não encontra evidências que comprovem a relação entre liberalização da conta de capital e financeira, medida pela variável share, e a variação real da renda per capita para o período entre 1975 e 1989. Eichengreen (2001) atribui esse resultado à quantidade de países em desenvolvimento na amostra de Rodrik, uma vez que trabalha com dados da década de 1980, período em que esse grupo de países, de forma generalizada, teve fraco desempenho econômico.

Kraay (1998) utilizando outras medidas de integração financeira ${ }^{6}$, além da share, também conclui que não há relação entre abertura da conta de capital e crescimento econômico para as medidas share e Quinn, mas confirma a relação quando utiliza a medida baseada nos fluxos de capital efetivos. $\mathrm{O}$ autor faz regressões cross-section para os dados do período.

Edison et al. (2002) também encontram poucas evidências suportando a tese de que integração financeira aceleraria as taxas de crescimento. Usando um conjunto variado de técnicas econométricas e medidas de integração baseadas nos fluxos de capitais reais, os autores não encontram relação entre as duas variáveis, mesmo quando controlando para características econômicas, políticas, institucionais e financeiras específicas. Por outro lado, encontram relação positiva entre integração financeira e o nível da renda per capita, taxa de matrículas escolares, desenvolvimento do setor bancário e mercado acio6 Utilizou a medida de Quinn em nível, cujos valores variam entre o e 4, e uma medida baseada no fluxo líquido real de capital. 
nário, sistema legal e relação negativa com o nível de corrupção do governo.

Damasceno (2008), trabalhando com um painel de 16 países da América Latina, para o período entre 1986 e 2000, não confirma a tese da aceleração do crescimento após a abertura financeira. Na mesma direção vai a conclusão de Bresser-Pereira e Gala (2007) que afirmam que a poupança externa associada a transações correntes deficitária não tem contribuído para aumentar a acumulação de capital e financiar crescimento, mas sim financia somente o consumo. Além disso, Bresser-Pereira (2007) recomenda que os países em desenvolvimento deveriam evitar o crescimento baseado em poupança externa, pois esta gera instabilidade relacionada com os déficits de conta corrente e a moeda sobrevalorizada.

Henry (2006), entretanto, questiona a validade destes testes, sugerindo que, na sua maioria, possuem equívocos metodológicos que poderiam distorcer os resultados obtidos. O autor não questiona os resultados dos referidos testes, mas o fato de que sejam utilizados para contestar a validade da teoria proposta a partir do modelo de Solow, porque simplesmente não testam esse modelo. Na opinião do autor, estes estudos testam, através de regressões cross-section, simplesmente a existência de correlação positiva entre abertura de capital e crescimento econômico, implicitamente medindo se existe uma relação permanente entre as duas medidas (Henry, 2006). Segundo o autor os testes precisam incorporar a dimensão do tempo e, portanto, deveriam utilizar técnicas estimação de séries temporais ou dados de painel.

Segundo Henry (2006), alguns dos principais estudos que compilam evidências empíricas sobre a validade da teoria neoclássica são Prasad et al. (2003), Edison et al. (2004), Calderon et al. (2004) e Kose et al. (2006). No primeiro artigo, dos quatorze estudos analisados, doze baseiam seus resultados em análises cross-section. No segundo estudo, nove dos dez estudos utilizam a referida metodologia. Por fim, nas outras duas pesquisas, onze de doze e vinte e dois de vinte e cinco estudos baseiam seus resultados em regressões cross-section, respectivamente. Em resumo, seus resultados gerais podem estar sendo decisivamente influenciados por este equívoco metodológico.

\section{Heterogeneidade dos Países e os Efeitos da Integração Financeira}

Estudos mais recentes apontam para uma mudança de direção nos esforços para se compreender os impactos do processo de abertura financeira. Estes estudos se afastam da visão simplificada de que a integração seria boa ou ruim para todos os países, ou mesmo para grupos de países como os em desenvolvimento.

Os autores questionam se o fato de muitos estudos não encontrarem evidência 
de impacto positivo da abertura da conta de capital sobre as taxas de crescimento não seria uma conseqüência de que muitos deles buscam encontrar uma relação incondicional entre as duas variáveis, enquanto que, na prática essa relação é mais complexa.

Alguns exemplos são os estudos de Klein e Olivei (1999), Edwards (2001) que visam testar a validade da teoria considerando, respectivamente, que as instituições ou o grau de desenvolvimento no estágio inicial de abertura podem influenciar os resultados alcançados. Os resultados obtidos confirmam a hipótese de que a integração financeira só teria efeito positivo sobre as taxas de crescimento para os países que possuem previamente um ambiente institucional favorável a alocação eficiente do capital, e um nível intermediário de desenvolvimento econômico7. Bordo e Meissner (2007) confirmam a tese de que os resultados da integração financeira não são incondicionais, utilizando dados entre 1880 e 1913. Para os autores os ganhadores deste processo são aqueles que apresentam alto nível de credibilidade internacional e mercado financeiro desenvolvido ${ }^{8}$. Calderón e Fuentes (2006) afirmam que o crescimento observado no Chile tem forte relação com a sua estabilidade macroeconômica, qualidade institucional e abertura financeira.

Calvo et al. (2008), entre outras coisas, argumentam que o risco de crises financeiras tende a crescer com a integração financeira quando partimos de níveis muito baixos de abertura ao fluxo de capitais, mas tende a reduzir para países que já estão em um nível elevado de integração. Além disso, afirma que a probabilidade da ocorrência de crises pode ser alterada quando esse processo é acompanhado por reformas que suportam instrumentos financeiros mais sofisticados e críveis.

Kose et al. (2009) também confirmam a tese de que os resultados da integração financeira podem depender das condições iniciais presentes em cada país. Segundo os autores, os principais elementos para potencializar os efeitos positivos do processo são: (1) desenvolvimento do mercado financeiro (principalmente do mercado de crédito), (2) qualidade das instituições, (3) abertura comercial, (4) rigidez do mercado de trabalho, e (5) nível geral de desenvolvimento do país. Além das condições iniciais destes elementos, a composição dos fluxos de capitais também influencia nos efeitos da integração9. Investimento Direto Estrangeiro (IDE) e Equity Flows são mais recomendáveis para países com baixo nível de desenvolvimento financeiro. Esse resultado é confirmado por Tong e Wei (2009).

Kose et al. (2009) chegam a outro resultado importante no seu estudo. Os

7 Ver Grilli e Milesi-Ferretti (1995); Edison et al. (2002); Broner e Ventura (2010).

8 Consideram mercado financeiro desenvolvido: (1) finanças públicas e gerenciamento da dívida pública corretos; (2) arranjos monetários estáveis; (3) competição no setor bancário interno e externo; (4) Banco central capaz de estabilizar o mercado financeiro doméstico e as relações com o resto do mundo; (5) mercado de securitizáveis funcionando adequadamente.

9 Goldstein et al. (2008) encontram evidências de que quanto maior a probabilidade do país sofrer crises de liquidez, maior a parcela de Investimento Estrangeiro de Curto Prazo (portfólio)/IDE na composição do fluxo de saída de capital. 
autores observaram que o desenvolvimento do mercado financeiro não é uma boa medida de estabilidade financeira. Eles afirmam que esta parece estar mais associada a estruturas regulatórias e de supervisão. Na próxima seção, abordaremos a importância dessas estruturas para o resultado do processo de integração.

A literatura recente também tem aberto uma nova frente para estudos relacionados ao tema. Esta decorre de observações como a de Obstfeld (2009), indicando que os dados mostram que, apesar de não existir evidências inequívocas dos benefícios do processo de integração financeira, os países têm aderido a esta estratégia como forma de acelerar seu crescimento. Tendo em vista que está cada vez mais claro que este é um processo inevitável, então o que nos cabe é identificar qual é a melhor forma de inserção nos mercados financeiros integrados. Para o autor, o que os países em desenvolvimento deveriam fazer é promover uma abertura gradual da sua conta de capital, dando prioridade para capitais de longo prazo e promovendo reformas que minimizem os riscos de crises futuras ${ }^{10}$.

Prasad e Rajan (2008), também constatando que o processo de integração financeira é inevitável, defendem o que chamam de uma abordagem pragmática à questão. Esta seria promover a abertura nos momentos em que o país possui elevados níveis de reserva, adotar sistema de metas de inflação e regime de câmbio flexível. Além disso, deveria privilegiar fluxo de investimento direto e não de dívida externa. Ao promover a abertura nestas condições, os custos do processo seriam reduzidos.

Nas próximas duas seções, em linha com a visão pragmática da integração financeira, veremos quais instituições têm papel determinante na canalização dos recursos para alocações eficientes e que medidas regulatórias poderiam ser tomadas para reduzir o risco de ocorrência de crises financeiras.

\section{O que fazer para que a Integração Financeira Beneficie os Países em Desenvolvimento}

A revisão da literatura feita até o momento indica, apesar das fragilidades metodológicas de alguns testes apresentados na seção anterior, que não existe benefício inequívoco da integração financeira para o crescimento do país, pelo menos quando o problema é analisado pela ótica da eficiência alocativa. Mishkin (2006) defende a idéia de que é o "bom investimento" que permite a transição das economias em desenvolvimento para níveis superiores de renda per capita, mas "bons investimentos" só seriam possíveis se os recursos financeiros fossem canalizados para os segmentos mais produtivos, através de um mercado financeiro eficiente. Ou seja, para o autor, o desenvolvimento do

$10 \mathrm{O}$ autor sugere controle de corrupção, reforçar a garantia de contratos, implantação de mecanismos de governança coorporativa e redução do endividamento em moeda estrangeira. 
mercado financeiro doméstico do país receptor dos fluxos de capital seria uma pré-condição para que a abertura financeira fosse capaz de gerar benefícios econômicos. A questão que se coloca é: como fazer isso? O caminho apontado seria o do desenvolvimento de instituições que permitam ao mercado financeiro funcionar adequadamente. O mesmo autor também defende a idéia de que para que os efeitos positivos da integração financeira se sobressaiam nos países em desenvolvimento, além de instituições que canalizem os recursos para os segmentos mais produtivos, seria necessário existir um conjunto de regramentos que reduzisse os riscos de ocorrência de crises financeiras de grandes proporções.

Nas próximas duas seções buscaremos identificar quais instituições auxiliam a alocação dos recursos nos setores mais produtivos e que conjunto de regulamentos reduz o risco de crises financeiras.

\subsection{Instituições e Investimento Produtivo Eficiente}

Para Mishkin (2006), os princípios básicos necessários para se alcançar o desenvolvimento do setor financeiro e fazer deste um catalisador do crescimento econômico seriam um conjunto de instituições que garantem: arcabouço legal que assegure os direitos de propriedade; um sistema de justiça que garanta contratos; redução da corrupção; sistema que garanta a qualidade das informações financeiras (sistema de classificação de risco); desenvolvimento de mecanismos de governança corporativa; e redução ou eliminação do sistema de crédito direcionado pelo governo.

A importância das instituições para potencializar os ganhos da integração financeira é reforçada por Bordo (2007). Através de uma ampla revisão da literatura, ele reúne evidências que explicam os resultados distintos dos países ao serem submetidos aos ciclos financeiros ao longo do tempo e destaca o papel do desenvolvimento financeiro dos países e suas raízes institucionais como sistema legal, proteção aos direitos de propriedade, estabilidade política e democracia representativa.

Outros estudos buscam estabelecer essa mesma relação. Lothian (2006) conclui que a qualidade das instituições pode ser a principal razão a explicar porque os recursos não migram dos países mais ricos para os mais pobres no volume esperado pela teoria. Simpalee e Breuer (2006) observam que tanto fatores econômicos como institucionais afetam a probabilidade de crises cambiais. Instituições de baixa qualidade acabam agravando o nível de dano sobre a contração do produto causado pelas crises financeiras. Os fatores que revelam maior relação com a probabilidade de crises são nível de corrupção, respeito à lei e a ordem, regime de câmbio fixo e fraqueza da estabilidade do governo. 
Sendo assim, se os benefícios econômicos do processo de integração dependem de um mercado financeiro eficiente e este, por sua vez, depende de instituições sólidas que estimulem investimentos produtivos, os países deveriam primeiro ajustar suas instituições para depois promover integração financeira. Estudos mostram que esse processo pode ocorrer simultaneamente e, mais ainda, as reformas necessárias poderiam ser aceleradas em função do engajamento do país em abrir tanto seu mercado financeiro como de mercadorias e serviços a outras nações ${ }^{11}$.

A exposição do mercado financeiro local à concorrência estrangeira pode estimular o desenvolvimento do mercado financeiro e o crescimento de duas formas: o primeiro é o tradicional argumento do aumento da oferta de capital e conseqüente redução do custo do capital, o segundo canal de contribuição seria o estímulo a reformas no setor financeiro, com a adoção de novas práticas trazidas por instituições financeiras de países mais desenvolvidos. A perda de espaço para competidores internacionais reduz a resistência das instituições locais a apoiar mudanças na legislação e nos regramentos de controle do sistema financeiro local ${ }^{12}$.

A limitação do setor financeiro em promover a alocação eficiente dos recursos financeiros, foi a principal razão apontada por Prasad et al. (2006) para justificar o fluxo de capital observado nos últimos anos, migrando dos países em desenvolvimento para os desenvolvidos, contradizendo o modelo neoclássico. Mercados financeiros ineficientes reduzem os retornos esperados do capital nos países em desenvolvimento, fazendo com que, ao invés de atrair capital estrangeiro dos países relativamente abundantes em capital (países desenvolvidos), o capital migre para estes mercados. Conclusão semelhante foi alcançada em Gourinchas e Jeanne (2007) e Buera e Shin (2009).

Alfaro et al. (2007) estuda as relações entre o fluxo de IDE e o crescimento econômico e também conclui que, mantendo a importância do IDE constante, economias cujos mercados financeiros são desenvolvidos tendem a crescer aproximadamente o dobro do observado em países com mercados financeiros pouco desenvolvidos. Incrementos na participação de IDE geram efeitos adicionais maiores sobre o crescimento nos países desenvolvidos financeiramente. Por sua vez, Mukerji (2009) conclui que a integração financeira tem um forte papel no desenvolvimento do setor financeiro e que este tem função determinante na redução da volatilidade da variação do PIB.

Por fim, existem formas indiretas de estimular o desenvolvimento do mercado financeiro. A principal delas e a abertura comercial do país, na medida em que para serem competitivas, as firmas exportadoras precisam ter acesso a capital com preços competitivos. A liberalização do comércio de mercadorias é uma poderosa arma para reduzir o poder político dos setores econômicos

11 Ver Kaminsky e Schmukler (2003); Ranciere et al. (2005). 
protegidos ${ }^{13}$. Ao promover maior competição nestes segmentos, reduz a renda dos mesmos, os estimulando a aceitar reformas institucionais que aumentem o acesso ao capital de forma mais eficiente ${ }^{14}$.

\subsection{Evitando as Crises Financeiras: instrumentos regula- tórios e fundamentos econômicos}

As crises financeiras ocorridas em países em desenvolvimento nos últimos anos são evidências que não podem ser ignoradas, ou seja, nem sempre o processo de integração financeira gera somente resultados positivos, principalmente nos países em desenvolvimento. Isso significa que economias menos desenvolvidas devam evitar a integração financeira? A resposta é não. O que deve ser feito é uma implementação cuidadosa da abertura destes mercados. A literatura nos aponta alguns condicionantes que se forem seguidos podem reduzir o risco da abertura levar a uma crise financeira de grandes proporções.

O argumento está de acordo com a visão de que se os países seguissem um processo de reformas e implementação de instrumentos regulatórios apropriados antes da abertura financeira, os risco de crises financeiras seriam reduzidos ${ }^{15}$.

\subsubsection{Regulação preventiva, supervisão e empoderamen- to das instituições reguladoras}

A primeira fonte de abalo do sistema financeiro é a falta de correspondência entre os passivos e os ativos das empresas (currency mismatch). Estas contratam dívidas em moeda estrangeira por diversas razões, como, por exemplo, evitar juros domésticos mais elevados e reduzir o risco inflacionário, mas percebem receitas em moeda corrente. Ao ocorrerem saídas mais bruscas de capital do país, gerando desvalorização da moeda doméstica, o fluxo de caixa destas companhias pode ficar comprometido, gerando risco de falências generalizadas.

Como aponta Allen et al. (2002), quase todas as crises recentes ocorridas nos países em desenvolvimento tiveram relação com a excessiva exposição das empresas domésticas em endividamento denominado em moeda estrangeira. Desta forma, as instituições responsáveis pela regulamentação do sistema bancário (uma vez que são os responsáveis pela intermediação financeira), deveriam limitar o nível de exposição das firmas a este tipo de endividamento. Com isso, provavelmente haveria maior estabilidade financeira nestes países ${ }^{16}$. 13 Mendoza et al. (2007) concluem que maior integração financeira estimula o desenvolvimento do setor financeiro gerando melhorias na distribuição de renda dos países.

14 Ver Svalaeyd e Vlachos (2002); Rajan e Zingales (2003).

15 Edwards (2008b) mostra que a integração financeira antes do aprofundamento da integração comer-

cial, por exemplo, aumenta a probabilidade de ocorrência de sudden stops.

16 Ver Kenen (2001). 
Este argumento é reforçado por Holland (2007) que comprova que o perfil da dívida externa influencia na vulnerabilidade externa ${ }^{17}$.

Outro fator relevante é a regulamentação do nível da relação capital/ativos totais dos bancos, evitando que tomem risco excessivo. Os parâmetros para a regulamentação podem ser diferentes para países em desenvolvimento e desenvolvidos. Nos EUA, uma instituição bancária é considerada capitalizada se essa relação é igual ou superior a $5 \%^{18}$. Além disso, nos países industrializados os ativos seguros são os títulos do governo. Isso não vale necessariamente para países em desenvolvimento. A crise do sistema bancário argentino, em 2001, esteve intimamente relacionada com o excessivo volume de títulos do governo detidos pelas instituições financeiras quando houve a decretação da moratória ${ }^{19}$.

Por fim, o sistema regulatório e de supervisão também deve orientar suas ações no sentido de avaliar o gerenciamento do risco das instituições financeiras e aumentar a "supervisão" do mercado através da obrigatoriedade da publicação dos balanços e avaliação de rating. Por mais que a imposição de limites à exposição ao risco possa contribuir para maior estabilidade do sistema, demonstram a situação de momento da instituição financeira, mas não capturam o nível do risco no futuro. Como o mercado financeiro é muito dinâmico, ações isoladas de agentes podem reverter rapidamente o nível de risco do banco ${ }^{20}$.

Naturalmente, de nada adianta um sistema de regulação e supervisão das atividades do sistema financeiro que não possua poder suficiente para agir com agilidade e independência para solucionar eventuais crises que venham a surgir. As autoridades devem ter o poder de exigir adequações de conduta quando identificam comportamento que pode levar a excessiva exposição ao risco das instituições financeiras e também punir os controladores das instituições insolventes pela conduta de risco assumida para evitar comportamento de risco moral (moral hazard) ${ }^{21}$. Esse problema tende a ser ainda maior nos países em desenvolvimento, uma vez que existe maior concentração no mercado financeiro.

Para tanto, as agências regulatórias deveriam ser independentes e possuir condições de trabalho adequadas para evitar seus agentes sejam capturados pelas instituições reguladas ${ }^{22}$.

\footnotetext{
17 Ver Bordo et al (2009).

18 A crise que assolou o sistema financeiro dos EUA a partir da metade de 2008 evidenciou, entretanto, sérios problemas relacionados aos mecanismos de regulação deste país, indicando que este não deve ser o modelo a ser seguido por outras economias.

19 Reinhart e Rogoff (2008) observam que crises bancárias geram efeitos fiscais severos. Observou-se que o aumento da dívida do governo central aumenta em média $86 \%$ após três anos do início da crise.

20 Ver Barth et al (2006).

21 Ver Mishkin (1992 e 2005).

22 Vu Le e Zak (2006) analisam painel de 45 países em desenvolvimento e testa o papel de três tipos de risco para se explicar a fuga de capitais: risco político, risco econômico e mudanças de política. Os três estão associados aos movimentos de capital, mas o risco político é o que apresenta maior impacto.
} 


\subsubsection{Abrir o mercado financeiro à concorrência estrangeira}

A abertura do mercado financeiro a instituições estrangeiras pode contribuir para a redução do risco de crises de duas formas, aumentando a estabilidade e a eficiência do sistema, conforme Caprio e Honohan (1999). A maior estabilidade do sistema pode ser obtida pelo fato de grandes bancos internacionais possuírem um portfolio de ativos mais diversificados do que dos bancos locais, uma vez que têm acesso a fundos de diversas partes do mundo através das suas subsidiárias. Sendo assim, esses bancos estão menos suscetíveis a choques econômicos domésticos do que os bancos nacionais.

Além disso, a entrada de bancos estrangeiros pode estimular a adoção de novas práticas de gerenciamento e controle de risco pelas instituições nacionais, em função da complexidade dos seus mercados locais. Uma vez que essas técnicas estejam disseminadas, o próprio mercado poderá passar a exigir controles mais modernos dos seus bancos.

Outra vantagem deste processo é a redistribuição de forças dentro do mercado financeiro doméstico. A entrada de bancos estrangeiros coloca em jogo agentes com poder econômico para se contrapor à estrutura vigente no mercado.

A maior participação de capital estrangeiro no sistema financeiro também desestimula a adoção de práticas de socorro de instituições bancárias com problemas financeiros. Os governos tendem a ser menos propensos ao socorro de instituições financeiras quando parte significativa do sistema é de propriedade estrangeira em função dos custos políticos que isso envolve ${ }^{23}$.

É importante que se ressalte, entretanto, que a entrada de bancos estrangeiros só será benéfica se aumentar a competição no mercado interno. Se houver a formação de monopólios ou oligopólios que reduzam a competição, eles podem não ter incentivos a serem eficientes e nem estimularem reformas institucionais.

\subsubsection{Fundamentos da economia}

As análises anteriores revelam que de uma forma ou outra as crises financeiras sofridas por países em desenvolvimento tem alguma relação com desequilíbrios internos do país que desencadeiam um ataque especulativo, resultando em fuga de capital ${ }^{24}$. Os instrumentos de política econômica (fiscal,

23 Ver Crystal et al. (2001).

24 Reinhart e Reinhart (2008) e Burnside e Tabova (2009), por outro lado, observam que fatores globais como preços de commodities, taxas de juros internacionais e crescimento das maiores economias influenciam decisivamente os fluxos de capitais e o próprio crescimento econômico das economias emergentes. Dooley e Hutchison (2009) mostram que apesar dos países emergentes terem adotado políticas que reduzissem seu grau de exposição aos choques externos, a crise do mercado imobiliário americano revelou que ainda há grande dependência do comportamento das economias emergente aos resultados das economias centrais. Fostel e Kaminsky (2007) mostram que o conjunto de políticas macroeconômicas e arranjo institucional explicam em parte os fluxos de capitais de um conjunto de países da América Latina, apesar de reconhecerem que a maior parte das flutuações sofridas foi resultado de choques externos. 
monetária, cambial e comercial) devem, portanto, ser utilizados para manter essa economia, como um todo, equilibrada ${ }^{25}$.

A política fiscal deve ser conduzida de forma a evitar déficits orçamentários excessivos. Uma medida importante para estimular responsabilidade fiscal é proibir, ou restringir, a capacidade do governo central auxiliar financeiramente estados ou municípios insolventes. Regras rígidas na condução de políticas de socorro desestimulam comportamentos de risco moral e "estados caronas", que repassam os custos do seu descontrole para os demais entes da federação.

Quando o governo central é leniente com o descontrole fiscal dos entes sub-nacionais, acaba-se gerando grandes passivos financiados por endividamento ou por emissão de moeda. As duas alternativas têm aspectos negativos importantes que podem desencadear crises financeiras. O endividamento elevado em países em desenvolvimento aumenta a exigência dos credores internacionais e pressiona os custos de rolagem da mesma. Quando o país se aproxima dos limites interpretados como de alto risco de default, inicia-se um processo de fuga de capitais desencadeando a chamada crise financeira.

O segundo problema associado ao nível de gastos do governo é a possibilidade de que surja a necessidade de financiamento monetário dos gastos e da dívida pública, gerando suas conseqüências inflacionárias já conhecidas. A estabilidade de preços é fundamental na promoção da estabilidade financeira, na medida em que ajuda a promover desenvolvimento financeiro e os benefícios associados a ele como redução do custo do capital, aceleração do crescimento e redução da pobreza ${ }^{26}$. Outras razões são apresentadas para justificar a importância da estabilidade de preços para reduzir os riscos dessas crises. Mishkin (2006) coloca que países com inflação elevada por períodos longos, ou que tenham vivido este problema por muito tempo, tendem a emitir dívida denominada em moeda estrangeira, normalmente dólar. Esse processo de dolarização da dívida aumenta o risco de crises financeiras em caso de desvalorização da moeda nacional. Desta forma, países que possuem uma estrutura institucional que garanta que o foco da política monetária será a busca da estabilidade de preços pode ser peça chave para que a integração financeira potencialize seus aspectos positivos, com baixo risco de crises financeiras sérias.

A política cambial também desempenha papel relevante neste processo. No final da década de 1980, início da década de 1990, muitos países em desenvolvimento que lutavam contra processos hiperinflacionários crônicos adotaram regimes de câmbio fixo, normalmente atrelando suas moedas ao dólar. Se, por um lado, essa medida ajudou na redução da inflação, por outro foi responsável

25 Edwards (2007b) conclui que deveremos observar a América Latina crescendo a taxas inferiores aos dos demais países em desenvolvimento, principalmente da Ásia. A principal razão é a percepção de que a região não esta fazendo nenhum movimento no sentido do aprofundamento de reformas institucionais. Fratzscher (2011) apresenta resultados que reforçam a importância dos fundamentos macroeconômicos em períodos de crise.

26 Ver Boyd et al. (2001). 
por sérios desequilíbrios que geraram crises financeiras muito graves ${ }^{27}$. Calvo e Mishkin (2003) destacam que mais importante do que o regime cambial para evitar crises financeiras, são as instituições fiscais e monetárias dos países em desenvolvimento. Se estas são capazes de preservar estabilidade fiscal e monetária, o regime de câmbio tem papel secundário na explicação do desempenho econômicos dos mesmos ${ }^{28}$.

A abertura comercial também é uma medida que pode reduzir a probabilidade de crises financeiras e, se ocorrerem, tende a ser menos severas. A distribuição de firmas operando no mercado doméstico e estrangeiro acaba funcionado como uma pulverização dos riscos inerentes a cada atividade econômica ${ }^{29}$.

Essa breve compilação de literatura nos permite ver que existem algumas condicionantes importantes a serem observadas para que a integração financeira potencialize o crescimento do país e não o coloque na rota de crises financeiras. Se os fundamentos da economia forem mantidos com qualidade (ou seja, política fiscal equilibrada, política monetária mantendo a inflação sob controle e integrada comercialmente com o resto do mundo), mercado financeiro integrado, e agências reguladoras independentes e com poder para fazer fiscalização preventiva adequada, a integração financeira ocorreria dentro de uma estrutura institucional amadurecida, reduzindo as chances de ocorrência de crises financeiras. Sendo assim, os aspectos positivos do processo de integração financeira tenderiam a prevalecer.

\section{Considerações Finais}

Iniciamos o estudo nos propondo a reunir evidências apontadas na literatura econômica acerca dos impactos do processo de integração financeira, seus aspectos positivos, negativos e sobre a existência de condicionantes que podem potencializar os seus benefícios e reduzir a probabilidade de crises.

Para responder a essas questões, o artigo foi organizado da seguinte forma: após uma breve introdução fazendo uma revisão histórica do processo de integração financeira, passamos a reunir a literatura que aponta a predominância de aspectos positivos deste processo. Mostramos que essa discussão teórica se apóia em vários pilares. O primeiro deles é o próprio conceito de integração financeira. Existem diversas formas de mensurar a integração, sendo algumas delas baseadas em informações qualitativas (chamadas de medidas de jure) e outras nos fluxos reais de capitais (chamadas medidas de fato). As diferentes medidas parecem influenciar nos resultados dos testes empíricos, portanto, é necessário que se continue aprimorando esse instrumento.

27 México em 1995, Brasil em 1998 e Argentina em 2001, são exemplos.

28 Edwards (2007a) destaca que o regime de câmbio flexível reduz a probabilidade dos países sofrerem reversões severas no fluxo de capital.

29 Edwards (2004), Frankel e Cavallo (2004) e Desai et al. (2005) são alguns exemplos de estudos empíricos que confirmam essa posição. 
Além disso, a literatura aponta para duas grandes fontes de ganhos econômicos a partir da integração financeira. A primeira fonte deriva do argumento da eficiência alocativa. Essa defende a idéia de que a abertura da economia para a entrada de capitais estrangeiros permite um barateamento do custo do capital, estimulando a acumulação de capital e consequentemente aumentando investimento e a taxa de crescimento da renda per capita (argumento derivado do modelo de Solow). A segunda fonte de ganho viria por canais indiretos que estimulariam o crescimento econômico também, com destaque para o estímulo a reformas institucionais. Além destas, a integração financeira também incentivaria maior responsabilidade na condução da política macroeconômica. Essas mudanças em elementos chave para o crescimento do país poderiam ser até as principais fontes de ganho advindos da integração.

Na terceira seção passamos a analisar os argumentos defendidos por autores que acreditam que o processo de integração financeira provocou mais malefícios do que benefícios para os países em desenvolvimento. Na opinião destes autores, deveríamos trabalhar separadamente os casos dos países desenvolvidos e dos países em desenvolvimento. Para estes, os testes empíricos que apontam ganhos com a integração, como aceleração das taxas de crescimento do produto per capita, são determinados primordialmente pela presença de países desenvolvidos na amostra. Esse grupo de países tenderia a ganhar com o processo, mas os países em desenvolvimento perderiam mais com a integração do que ganhariam com ela, pois tendem a sofrer crises financeiras severas que reduzem drasticamente seus níveis de renda.

Essa posição é contestada por alguns autores que criticam os métodos utilizados nos testes empíricos aplicados. A principal crítica é que esses estudos testam relações de aceleração do crescimento a longo prazo e não a curto prazo, como preconizado no modelo neoclássico. Além disso, os modelos são baseados em testes cross-section, ignorando o caráter temporal do impacto da integração financeira. Em resumo, defendem a idéia de que os testes precisam evoluir e passar a utilizar métodos de série de tempo ou dados de painel. Mais ainda, questões relacionadas à amostra de países analisados podem influenciar os resultados dos testes.

Na seqüência, reunimos a literatura mais recente que vem consolidando a idéia de que os resultados da integração são heterogêneos entre os países, mesmo entre os emergentes. As evidências indicam que as condições iniciais dos países (suas características institucionais, desenvolvimento do mercado financeiro, abertura comercial, regime cambial, entre outros fatores) ao serem expostos à integração financeira podem influenciar os resultados subseqüentes.

Por essas razões, o debate continua aberto. As dificuldades metodológicas que limitam a capacidade dos pesquisadores chegarem a uma conclusão definitiva sobre os impactos da integração financeira, se predominam seus efeitos positivos (como maior eficiência alocativa e benefícios indiretos) ou seus efeitos negativos (crises financeiras), estimulam uma mudança no objeto central dos questionamentos. Ao se reconhecer que os dois grupos de resultados podem 
ocorrer, ou seja, aparentemente os benefícios à abertura da conta de capital não são inequívocos, mais do que perguntar se a integração financeira gera resultados positivos aos países, parece mais adequado perguntar o que é necessário ser feito para que os efeitos positivos da integração predominem e os riscos de crises financeiras sejam reduzidos.

A seção cinco do estudo se propõe a buscar essas respostas. A literatura aponta dois grupos de elementos importantes. O primeiro conjunto teria papel determinante na alocação eficiente do capital e o segundo seria um grupo de precondições recomendáveis que reduziriam a probabilidade de ocorrência de crises financeiras.

A alocação eficiente do capital pode ser influenciada por um conjunto de instituições específicas. Estas seriam: arcabouço legal que assegure os direitos de propriedade; um sistema de justiça que garanta contratos; redução da corrupção; sistema que garanta a qualidade das informações financeiras (sistema de classificação de risco); desenvolvimento de mecanismos de governança corporativa; e redução ou eliminação do sistema de crédito direcionado pelo governo.

A probabilidade de ocorrência de crises financeiras pode ser afetada por quatro elementos básicos: existência de sistema de regulamentação e supervisão preventiva, para evitar que instituições financeiras se exponham excessivamente ao risco; agencias reguladoras independentes; abertura do sistema bancário para instituições estrangeiras, reduzindo o poder político das instituições nacionais, trazendo novas práticas e estimulando reformas que aumentem a eficiência do sistema financeiro nacional; e, por fim, manter a economia como um todo com bons fundamentos, reduzindo o risco de desequilíbrio interno sérios no que tange à situação fiscal, taxa de inflação e política comercial.

Desta forma, vimos que a literatura econômica não alcançou consenso quanto às vantagens do processo de integração financeira, principalmente nos países em desenvolvimento. Se, por um lado, existem ganhos potenciais na eficiência da alocação do capital, como preconizado no modelo neoclássico, por outro, existem riscos de que fugas de capitais gerem danos severos sobre a atividade econômica dos mesmos. Entretanto, pode-se afirmar que o amadurecimento do debate tem apontado para um conjunto de questões novas que merecem maior atenção dos estudiosos do tema. Mais do que perguntar se a integração financeira gera efeitos positivos sobre a renda ou crise financeira, parece mais relevante observarmos que este processo pode gerar efeitos indiretos significativos sobre as economias em desenvolvimento, estimulando reformas e boas práticas na condução de políticas macroeconômicas. Além disso, devemos explorar mais as proposições que indicam que, se os países observarem algumas condições iniciais, os riscos de crises financeiras podem ser reduzidos, potencializando os ganhos da abertura. Por fim, poderíamos ir além e questionar qual é a relação de causalidade entre essas "condições iniciais" e os resultados da integração. Será que as referidas condições não podem surgir estimuladas pelo próprio processo de abertura financeira? Questões 
como estas restam em aberto, e merecem ser analisadas em estudos futuros.

\section{Referências}

Alfaro, L. et al. (2007). "How does foreign direct investment promote economic growth? Exploring the effects of financial markets on linkages". NBER Working Paper no 12522.

Allen, M. et al. (2002). "A balance-sheet approach to financial crises”. IMF Working Paper $n^{\underline{o}}$ 02/210.

Barth, J.; Caprio, G.; Levine, R. (2006). Rethinking bank regulation and supervision: til angels govern. New York: Cambridge University Press.

Bekaert, G. (1995). "Market integration and investment barriers in emerging equity markets". World Bank Economic Review, v. 9, pp. 75-107, jan.

Bekaert, G.; Harvey, C. (1995). “Time-varying world market integration”. Journal of Fiance, v. 50, pp. 403-44.

Bekaert, G.; Harvey, C. (2002). Chronology of important financial, economic and political events in emerging markets. URL [on-line]: <http://www.duke. edu/ charvey/chronology.htm>. Acesso em: $18 \mathrm{dez} .2009$.

Bekaert, G.; Harvey, C.; Lundblad, C. (2005). "Does financial liberalization spur growth?” Journal of Financial Economics, n. 77, pp. 3-35.

Bordo, M. (2007). “Growing up to financial stability”. NBER Working Paper $n^{\circ}$ 12993.

Bordo, M.; Meissner, C. (2007). "Foreign capital and economic growth in the first era of globalization”. NBER Working Paper $n^{-} 13577$.

Bordo, M; Meissner, C.; Stuckler, D. (2009). "Foreign currency debt, financial crises and economic growth: a long run view”. NBER Working Paper $n^{\underline{0}} 15534$.

Boyd, J.; Levine, R.; Smith, B. (2001). "The impacts of inflation on financial sector performance”. Journal of Monetary Economics, v. 47 (2), pp. 221-48.

Bresser-Pereira, L. (2007). "Economia política da desgovernança global”. Estudos Econômicos, São Paulo, v. 37 (3), pp. 463-486.

Bresser-Pereira, L.; Gala, P. (2007). "Por que a poupança externa não promove crescimento". Revista de Economia Política, v. 27 (1), pp. 3-19.

Broner, F.; Ventura, J. (2010). "Rethinking the effects of financial liberalization". NBER Working Paper no 16640.

Buera, F.; Shin, Y. (2009). "Productivity growth and capital flows: the dynamics of reforms". NBER Working Paper no 15268.

Burnside, C.; Tabova, A. (2009). "Risk, volatility, and the global cross-section of growth rates”. NBER Working Paper $n^{\circ} 15225$.

Calderon, C.; Loayza, N.; Schmidt-Hebbel, K. (2004). "Openness, vulnerability, and growth". Working Paper, Central Bank of Chile.

Calderon, C.; Fuentes, R. (2006). "Complementarities between institutions and 
openness in economic development: evidence for a panel of countries”. Cuadernos de Economía, v. 43, pp. 49-80.

Carvalho, B.; Garcia, M. (2006). "Ineffective controls on capital inflows under sophisticated financial markets: Brazil in the nineties". NBER Working Paper $n^{\mathrm{o}} 12283$.

Calvo, G.; Izquierdo, A.; Mejía, L. (2008). "Systemic sudden stops: the relevance of balance-sheet effects and financial integration”. NBER Working Paper $n^{\circ}$ 14026.

Calvo, G.; Mishkin, F. (2003). “The miracle of exchange rate regimes for emerging market countries”. Journal of Economic Perspectives, v. 17 (4), pp. 99-118.

Caprio Jr., G.; Honoran, P. (1999). "Restoring banking stability: beyond supervised capital requirements". Journal of economic perspectives, v. 13 (9), pp. 43-64.

Chandra, A. (2001). "The influence of capital controls on long-run growth: where and how much?” Mimeo.

Cipriani, M.; Kaminsky, G. (2006). "Volatility in international financial market issuance: The role of the financial center". NBER Working Paper $n^{\underline{0}} 12587$.

Crystal, J.; Dages, G.; Goldberg, L. (2001). “Does foreign ownership contribute to sounder banks in emerging markets? The Latin American experience”. In: Litan, R.; Masson, P.; Pomerleano, M. (Ed.). Open doors: foreign participation in financial systems in developing countries. Washington, D.C.: Brooking Institution Press, pp. 217-66.

Damasceno, A. (2008). "Liberalização da conta de capitais e crescimento econômico: evidências de dados em painel para a América Latina”. Revista de Economia Política, v. 28 (4), pp. 595-611.

Desai, M.; Foley, F.; Hines, J. (2005). Capital controls, liberalizations and foreign direct investment. NBER Working Paper $n^{\underline{o}} 10337$.

Dooley. M.; Hutchison, M. (2009). "Transmission of the U.S. Subprime crisis to emerging markets: Evidence on the decoupling-recoupling hypothesis". NBER Working Paper $n^{\underline{o}} 15120$.

Edison, H. et al. (2002). International financial integration and economic growth. Journal of International Money and Finance, n. 21, pp. 749-76.

Edison, H.; Warnock, F. (2003). A simple measure of the intensity of capital controls. Journal of Empirical Finance, v. 10, pp. 81-103.

Edison, H. et al. (2004). "Capital account liberalization, and economic performance: synthesis and survey”. IMF Staff Papers, v. 51 (2), pp. 220-256.

Edwards, S. (2001). "Capital Mobility and economic performance: are emerging economies different?” NBER Working Paper $n^{\circ} 8076$.

Edwards, S. (2004). "Financial openness, sudden stops and current account reversals". NBER Working Paper $n^{\circ} 10277$.

Edwards, S. (2007a). "Capital controls, capital flows, and macroeconomic vulnerability”. NBER Working Paper no 12852.

Edwards, S. (2007b). “Crises and growth: a Latin American perspective”. NBER 
Working Paper no 13019.

Edwards, S. (2008a). "Globalization, growth and crises: The view from Latin America”. NBER Working Paper no 14034.

Edwards, S. (2008b). "Sequencing of reforms, financial globalization, and macroeconomic vulnerability”. NBER Working Paper $n^{\circ} 14384$.

Eichengreen, B. (2001). "Capital account liberalization: what do cross-country studies tell us?” The World Bank Economic Review, v. 16 (3), pp. 341-65.

Fostel, A.; Kaminsky, G. (2007). "Latin America's access to international capital markets: good behavior or global liquidity?” NBER Working Paper $n^{0} 13194$.

Frankel, J.; Cavallo, A. (2004). "Does openness to trade make countries more vulnerable to sudden stops or less? Using gravity to establish causality”. NBER Working Paper n⿳⺈ 10957.

Fratzscher, M. (2011). "Capital flows, push versus pull factors and the global financial crisis”. NBER Working Paper $n^{\circ} 17357$.

Goldstein, I.; Razin, A.; Tong, H. (2008). "Liquidity, institutional quality and the composition of international equity outflows". NBER Working Paper $n^{\circ}$ 13723 .

Gourinchas, P.; Jeanne, O. (2007). Capital flows to developing countries: The allocation puzzle. NBER Working Paper $n^{\circ} 13602$.

Grilli, V.; Milesi-Ferretti, G. (1995). "Economic effects and structural determinants of capital controls". IMF Staff Papers, v. 42 (3), pp. 517-51.

Henry, P. (2000a). "Stock market liberalization, economic reform, and emerging market equity prices". Journal of Finance, v. 55 (2), pp. 529-64.

Henry, P. (200ob). "Does stock market liberalization cause investment booms?" Journal of Financial Economics, v. 58, n. 1-2, pp. 301-34.

Henry, P. (2006). "Capital account liberalization: theory, evidence, and speculation”. NBER Working Paper no 12698.

Henry, P.; Sasson, D. (2008). "Capital account liberalization, real wages, and productivity”. NBER Working Paper $n^{\circ} 13880$.

Henry, P.; Sasson, D. (2009). Capital market integration and wages. NBER Working Paper $n^{\circ} 15204$.

Holland, M. (2007). External debt in developing economies: assessment and policy issues. Brazilian Journal of Political Economy, v. 27 (1), pp. 20-40.

Kalemli-Ozcan, S.; Sorensen, B.; Volosovych, V. (2010). "Deep financial integration and volatility". NBER Working Paper $n^{\circ} 15900$.

Kaminisky, G.; Schmukler, S. (2003). "Short-run pain, long-run gain: the effects of financial liberalization”. NBER Working Paper $n^{\circ} 9787$.

Kenen, P. (2001). “The international financial architecture: what's new? What's missing?” Washington, D.C: Institute of International Economics.

Klein, M.; Olivei, G. (1999). "Capital account liberalization, financial depth and economic growth”. NBER Working Paper $n^{-} 7384$.

Klein, M.; Olivei, G. (2005). "Capital account liberalization, institutional quality 
and economic growth: theory and evidence”. NBER Working Paper $n^{\circ} 11112$.

Kose, M. et al. (2006). "Financial globalization: a reappraisal”. NBER Working Paper $n^{\circ} 12484$.

Kose, M.; Prasad, E.; Taylor, A. (2009). "Thresholds in the Process of International Financial Integration”. NBER Working Paper $n^{\underline{0}} 14916$.

Kose, M.; Prasad, E.; Terrones,M. (2008). Does openness to international financial flows raise productivity growth? NBER Working Paper $n^{\circ} 14558$.

Kraay, A. (1998). "In search of the macroeconomic effects of capital account liberalization". World Bank.

Lane, P.; Milesi-Ferretti, M. (2001). "The external wealth of nations: measures of foreign assets and liabilities for industrial and developing nations". Journal of International Economics, v. 55 (2), pp. 263-94.

Levine, R.; Zervos, S. (1998). “Stock market, banks, and economic growth'. American Economic Review, v. 88, pp. 537-58.

Lindert, P.; Williamson, J. (2001). "Does globalization make the world more unequal?' NBER Working Paper no 8228.

Lothian, J. (2006). "Institutions, capital flows and financial integration". Journal of International Money and Finance, v. 25, pp. 358-369.

Magud, N.; Reinhart, C. (2006). "Capital controls: An evaluation”. In: Edwards, S. (ed.). International Capital Flows. University of Chicago Press.

Mendoza, E.; Quadrini, V.; Rios-Rull, J. (2007). "On the welfare implications of financial globalization without financial development”. NBER Working Paper $n^{\circ} 13412$.

Mishkin, F. (1992). "An evaluation of the treasury plan for banking reform”. Journal of Economic Perspectives, v. 6 (1), pp. 133-153.

Mishkin, F. (2005). "How big is a problem too big to fail?” NBER Working Paper $n^{\circ} 11814$.

Mishkin, F. (2006). The next great globalization: how disadvantaged nations can harness their financial systems to get rich. Princeton University Press.

Montiel, P.; Reinhart, C. (1999). "Do capital controls and macroeconomic policies influences the volume and composition of capital flows?" Evidence from the 1990s. Journal of International Money and Finance, v. 18 (4), pp. 619-135.

Mukerji, P. (2009). “Ready for capital account convertibility?” Journal of International Money and Finance, v. 28, pp. 1006-1021.

Obstfeld, M. (2009). "International finance and growth in developing countries: What have we learned?” NBER Working Paper $n^{\circ} 14691$.

Pires, J. (2006). "O efeito da liberalização da conta de capital sobre a política fiscal: Uma avaliação do caso brasileiro recente". Revista de Economia Política, v. 26(2), pp. 258-73.

Prasad, E. (2009). "Some new perspectives on India's approach to capital account liberalization”. NBER Working Paper no 14658.

Prasad, E. et. al. (2003). "Effects of financial globalization on developing coun- 
tries; some new evidence". IMF Occasional Paper $n^{\circ} 220$.

Prasad, E.; Rajan, R.; Subramanian, A. (2006). "Foreign capital and economic growth”. IMF Research Department, 2006. Mimeo.

Prasad, E.; Wei, S. (2007). “The Chinese approach to capital inflows: patterns and possible explanations”. In: EDWARDS, S. (Ed.). International Capital Flows. Chicago: University of Chicago Press.

Prasad, E.; Rajan, R. (2008). “A pragmatic approach to capital account liberalization”. NBER Working Paper $n^{\circ} 14051$.

Quinn, D. (1997). “The correlates of change in international financial regulations". American Political Science Review, v. 91(3), pp. 531-51.

Rajan, R.; Zingales, L. (2003). "The great reversal: The politics of financial development in the $20^{\text {th }}$ century". Journal of Financial Economics, v. 69 (1), pp. 5-50.

Ranciere, R.; Tornell, A.; Westermann, F. (2005). "Systematic crises and growth". NBER Working Paper $n^{\circ} 11076$.

Ranciere, R.; Tornell, A.; Westermann, F. (2006). "Decomposing the effects of financial liberalization: Crises vs. growth”. NBER Working Paper $n^{\circ} 12806$.

Reinhart, C.; Rogoff, K. (2008). "Banking crises: An equal opportunity menace. NBER Working Paper $n^{\underline{0}} 14587$.

Reinhart, C.; Reinhart, V. (2008). "Capital flow bonanzas: An encompassing view of the past and present”. NBER Working Paper $n^{\circ} 14321$.

Rodrik. D. (1998). “Who needs capital account convertibility?” Princeton Essays in International Finance, v. 207, pp. 55-65.

Rose, A.; Spiegel, M. (2008). "International financial remoteness and macroeconomic volatility”. NBER Working Paper $n^{\circ} 14336$.

Simpalee, P.; Breuer, J. (2006). "Currency crises and institutions”. Journal of International Money and Finance, v. 25, pp. 125-145.

Svalaeryd, H.; Vlachos, J. (2002). "Market for risk and openness to trade: How are they related?” Journal of International Economics, v. 57 (2), pp. 364-95.

Solow, R. (1956). “A contribution to the theory of economic growth”. Quarterly Journal of Economics, n. 70, pp. 65-94.

Tong, H.; Wei, S. (2009). “The composition matters: capital inflows and liquidity crunch during a global economic crisis". NBER Working Paper $n^{\circ} 15207$.

Vu Le, Q.; Zak, P. (2006). "Political risk and capital flight”. Journal of International Money and Finance, v. 25, pp. 308-329. 
